\title{
Is Positive Staining of Non-Functioning Pituitary Adenomas for Luteinizing Hormone Associated with a Poor Prognosis?
}

\author{
Halit DIRI ${ }^{1}$, Ersin OZASLAN ${ }^{2}$, Ali KURTSOY ${ }^{3}$, Bulent TUCER ${ }^{3}$, Yasin SIMSEK ${ }^{1}$, Figen OZTURK ${ }^{4}$, \\ Ahmet Candan DURAK ${ }^{5}$, Sirac ERTEN ${ }^{4}$, Fahri BAYRAM ${ }^{1}$ \\ ${ }^{1}$ Erciyes University, Medical School, Department of Endocrinology, Kayseri, Turkey \\ ${ }^{2}$ Erciyes University, Medical School, Department of Medical Oncology, Kayseri, Turkey \\ ${ }^{3}$ Erciyes University, Medical School, Department of Neurosurgery, Kayseri, Turkey \\ ${ }^{4}$ Erciyes University, Medical School, Department of Pathology, Kayseri, Turkey \\ ${ }^{5}$ Erciyes University, Medical School, Department of Radiology, Kayseri, Turkey
}

\section{ABSTRACT}

AIM: The aim of this study was to assess the relationships among immunohistochemical staining patterns and prognostic factors in patients with non-functioning pituitary adenoma (NFPA).

MATERIAL and METHODS: The study included 103 patients who had undergone pituitary surgery for NFPAs. The prognostic factors evaluated were initial tumor size, cavernous sinus invasion, compression of the optic chiasm, recurrence, residual tissue, reoperation, and hypopituitarism.

RESULTS: Recurrence rates were higher for NFPAs with large initial tumor volume and preoperative cavernous sinus invasion. Tumor recurrence rates were higher for NPFAs positive $(55.6 \%)$ than negative (10.3\%) for luteinizing hormone (LH). Reoperation rate, but not recurrence rate, was higher in patients with tumors positive than negative for follicle-stimulating hormone (FSH) group. Recurrence and reoperation rates were lowest in patients with null-cell adenomas.

CONCLUSION: In contrast to previous studies, we observed a higher recurrence rate in LH-positive than in LH-negative adenomas. To our knowledge, this is the first study showing an association between LH positivity and poorer prognosis; and in addition, optimal outcomes in patients with null-cell adenomas. Thus, additional studies are required to assess the relationship between LH positivity and poor prognosis in patients with NFPAs.

KEYWORDS: Non-functioning pituitary adenomas, Luteinizing hormone, Immunohistochemistry, Prognosis

\section{INTRODUCTION}

Non-functioning pituitary adenomas (NFPAs), which account for $25-30 \%$ of all pituitary adenomas, may immunohistochemically be positive for follicle-stimulating hormone (FSH), luteinizing hormone (LH), alpha subunit, adrenocorticotrophic hormone (ACTH), thyroid-stimulating hormone (TSH), growth hormone $(\mathrm{GH})$, and prolactin $(2,13,24)$. However, they generally do not secrete any clinically relevant hormones $(7,26)$.

Similar to functioning pituitary adenomas, NFPAs are typically benign tumors, although some may be locally invasive and grow rapidly $(15,16,28)$. Local invasion can involve the cavernous sinuses, sphenoid sinuses, clivus, optic nerves and even the third ventricle. These invasive tumors constitute a group of pituitary tumors with biological behaviors between pituitary adenomas and carcinomas (5). They differ from pituitary carcinomas only in the absence of metastases. Features associated with clinically aggressive behavior include larger tumor size, resistance to treatment, invasion of surrounding structures, tumor recurrence, and proliferation of residual tissue. 
Factors affecting the prognosis of pituitary adenomas include patient age, invasion of the cavernous and/or sphenoid sinuses, immunocytochemical staining patterns, the cell cycle markers including $\mathrm{Ki}-67$ and mitotic index, and p53 concentration (23). A recent meta-analysis showed that postoperative prognosis in patients with functioning pituitary adenomas was correlated with initial tumor size, cavernous sinus invasion, and low postoperative hormone concentration. Although the postoperative remission rate in patients with NFPA was lower (44.4\%), no factor was found to precisely predict NFPA recurrence in that study (21).

The immunohistochemical staining patterns of pituitary adenomas may be prognostic of recurrence in patients with NFPAs. Thus, determining staining characteristics may lead to early recognition and better management of patients with patterns prognostic of recurrence. This study was therefore designed to assess the relationships between immunohistochemical staining patterns and prognostic factors in patients who underwent NFPA resection.

\section{MATERIAL and METHODS}

\section{Study Design}

The medical records of 182 consecutive patients who underwent pituitary surgery for NFPA by the same neurosurgeon (A.K.) at the Neurosurgery Department of Erciyes University Medical School between 2000 and 2012 were evaluated. Seventy-nine patients were excluded due to missing hormonal or magnetic resonance imaging (MRI) results before or after surgery or due to radiotherapy or medical therapy. Thus, this retrospective study evaluated 103 patients who had undergone pituitary surgery. Their demographic data, dates of surgery, total follow-up periods, results of immunohistochemical staining, preoperative and postoperative hormonal data and MRI results were recorded. A definitive diagnosis of NFPA was based on preoperative hormonal evaluation and pathological examination of resected pituitary tumor tissue. Factors used to evaluate prognosis included preoperative and postoperative unilateral or bilateral cavernous sinus invasion, compression of the optic chiasm, tumor recurrence, initial tumor size, residual tissue, reoperation, and hypopituitarism.

\section{Patients}

The inclusion criteria were age $\geq 18$ years, available hormonal and MRI results before and after surgery, and immunohistochemical evaluations of pituitary adenomas. The exclusion criteria were age $<18$ years, radiotherapy or medical therapy due to NFPA, and lack of radiological or hormonal evaluation before or after surgery. Patients with recurrence were followed-up for at least 2 years and patients without recurrence were followed-up for at least 5 years postoperatively. The criterion for including patients who did not regularly attend clinical visits was being followed up within the previous 2 years.

\section{Assessment of Pituitary Functions}

Basal and, if indicated, dynamic hormone tests were performed to determine whether adenomas were functioning or non-functioning and whether there were any postoperative deficiencies in anterior pituitary hormones. Hormone concentrations were measured preoperatively, 3 days, 2 weeks, and $1,3,6$, and 12 months postoperatively, and at least annually thereafter. Basal hormones included ACTH, cortisol, TSH, free $\mathrm{T} 4$, free T3, prolactin, GH, insulin-like growth factor-I (IGF-I), $\mathrm{FSH}$, and $\mathrm{LH}$. In addition, total testosterone was measured in male subjects, and estradiol in female subjects. All of these assays were performed at the biochemistry laboratory of Erciyes University Medical School. Pituitary adenomas that resulted in mild hyperprolactinemia $(<50 \mathrm{ng} / \mathrm{ml})$ and that were attributable to compression of the pituitary stalk were not evaluated as prolactinomas. In addition, none of these adenomas were stained positively for prolactin. Postoperative pituitary hormone deficiencies were evaluated as prognostic factors, whereas preoperative deficiencies that recovered after surgery were not considered.

\section{Imaging Studies}

Patients underwent pituitary 3-dimensional volumetric MRI (Philips, 1.5Tesla, Netherlands) beforethe initialsurgery, at which time the largest diameters of the adenomas were measured. Adenomas $<10 \mathrm{~mm}$ were considered microadenomas, those $\geq 10 \mathrm{~mm}$ were considered macroadenomas, and those $>40$ $\mathrm{mm}$ in diameter were defined as giant adenomas. Follow-up pituitary MRI was performed every 6 months during the first two years and yearly thereafter.

\section{Pathological Evaluations}

Resected tumor specimens were analyzed at the Pathology Department of Erciyes University. Pathological evaluations included gross, microscopic and immunohistochemical evaluations. All tissue samples were immersed in $10 \%$ formaldehyde for 24 hours and subjected to routine tissue tracing procedures. Cross-sections were obtained after paraffin embedding. These cross-sections were stained with hematoxylin-eosin and afterwards with antibodies against FSH, LH ACTH, GH, PRL, and TSH. Immunohistochemical analyses were performed by an automatic device called 'Ventana Benchmark XT' and primary antibodies called 'Universal DAB Detection Kit' were used. Most of the tumor samples were not evaluated for Ki-67 nuclear labeling index and level of mitotic activity. In addition, an antibody against alpha-subunit was not available. Strong and diffuse staining with antibodies was regarded as positive, whereas weak $(<5 \%$ of tumor cells) staining was considered negative. On the basis on immunohistochemical results, the NFPAs were classified as $\mathrm{LH}+, \mathrm{FSH}+, \mathrm{FSH} \& \mathrm{LH}+, \mathrm{ACTH}+$, and null-cell adenomas. Additionally, stained adenomas were divided into two as 'all positives' and 'only positives'. For example, in case of strongly positive staining with FSH alone, it was classified in both groups of 'only FSH positives' and 'all FSH positives'. Additionally, in case of an adenoma strongly stained with both $\mathrm{FSH}$ and $\mathrm{LH}$, it was classified in all three groups of 'all FSH positives', 'all LH positives', and 'both FSH and LH positives'. All pathological examinations were performed by the same pathologist (F.O.) who was blinded to all clinical data. In 6 patients who had undergone pituitary surgery twice or more, there were distinct pathology results for each surgery. In these 
patients, only the pathology results of the most successful surgery, defined as removing the largest volume of tumor tissue, were analyzed.

\section{Assessment of Recurrence}

Recurrence was defined as reappearance of a tumor following complete resection or an increase in size of residual tissues on MRI. Reoperations performed during the first year after initial surgery due to residual tumors that were not growing or complications such as rhinorrhea or apoplexy were considered reoperations, not recurrences.

\section{Statistical Analysis}

All statistical analyses were performed using SPSS for Windows version 15.0 (SPSS Inc., Chicago, IL.). Data are reported as mean \pm standard deviation (SD). The distribution of data was tested by the Kolmogorov-Smirnov test before comparison and correlation tests. Chi-square tests were used to compare groups, and the Spearman test was used for correlation analyses. A $p$ value $<0.05$ was considered statistically significant.

\section{RESULTS}

Of the 103 patients with NFPAs, 58 were male and 45 were female. Mean patient age was $56.9 \pm 11.6$ years and mean follow-up period was $7.1 \pm 2.6$ years. Of the patients, 76 $(73.8 \%)$ had macroadenomas, and $27(26.2 \%)$ had giant adenomas, but none had microadenomas. Mean initial tumor size was $31.2 \pm 9.7 \mathrm{~mm}$, and tumor size was significantly correlated with tumor recurrence, residual tumor, reoperation, panhypopituitarism, cavernous sinus invasion, and optic chiasm compression $(p<0.05)$.

Residual tumors were observed in 84 patients (81.6\%), with regrowth of residual tumor (i.e., recurrence) observed in 31 $(30.1 \%)$. None of the patients with totally resected tumors experienced a tumor relapse. The mean follow-up time to tumor recurrence was $6.6 \pm 3.6$ years. Partial and complete hypopituitarism was observed in 46 (44.7\%) and 25 (24.3\%) patients, respectively. Taken together, $81(78.6 \%)$ patients in total had postoperative hypopituitarism.

Immunohistochemical analyses of the removed adenomas are shown in Table I. Three $(2.9 \%)$ adenomas were positive for ACTH alone, two others (1.9\%) were positive for ACTH and at least one other marker, 11 (10.7\%) were positive for FSH alone, 18 (17.5\%) were positive for FSH and other markers, 25 (24.3\%) were positive for $\mathrm{LH}$ alone, 20 (19.4\%) were positive for LH and other markers, 18 (17.5\%) were positive for both FSH and LH, and 36 (35\%) were negative for all markers tested. Thus, of the 103 adenomas, 54 (52.4\%) were gonadotroph adenomas (positive for FSH and/or LH), 36 (35\%) were nullcell adenomas, $3(2.9 \%)$ were silent corticotroph adenomas, and 5 (4.9\%) were silent plurihormonal adenomas.

The distribution of patients according to tumor staining patterns and prognostic factors is shown in Table II. The recurrence rate was significantly higher in patients positive for $\mathrm{LH}$ alone $(15 / 25=60 \%)$ than the other patients who were not positive for LH alone $(16 / 78=20.5 \% ; p<0.001)$. Recurrence $(p<0.001)$ and reoperation $(p=0.005)$ rates were also significantly higher in patients positive for $\mathrm{LH}$, including those positive for other markers (all LH positives), than in patients negative for $\mathrm{LH}$. Tumor recurrence rate was $55.6 \%(25 / 45)$ in NPFAs positive for $\mathrm{LH}$ (all LH positives), while 10.3\% (6/58) in NPFAs negative for $\mathrm{LH}$. The rate of reoperation was significantly higher in patients positive for FSH than in patients negative for $\mathrm{FSH}$ $(p=0.012)$. In contrast, recurrence and reoperation rates were significantly lower in patients with null-cell adenomas than in all other groups; recurrence was observed in only 3 of $36(8.3 \%)$ of null-cell adenoma patients. Furthermore, no significant relationship was observed between ACTH staining patterns and prognosis.

Of the 103 patients with NFPA, 89 (86.4\%) showed compression of the optic chiasm before surgery, and 19 (18.4\%) after surgery. Cavernous sinus invasion was observed in 81 patients (78.6\%) before surgery and in $49(47.6 \%)$ patients after surgery. Preoperative cavernous sinus invasion was significantly associated with tumor recurrence. Recurrence was observed in 30 of $81(37 \%)$ patients with, compared with 1 of $22(4.5 \%)$ without, preoperative cavernous sinus invasion $(p=0.003)$. The presence of postoperative remnants was also associated with recurrence $(p=0.002)$; recurrence was observed in 31 of 84 $(36.9 \%)$ patients with residual tumors but in none of 19 patients without residual tumors. Furthermore, 31 (30.1\%) patients had undergone pituitary surgery twice or more.

\section{DISCUSSION}

Obviously, the surgeon's ability is an important factor in the postoperative prognosis of pituitary adenomas. Additionally,

Table I: Immunohistochemical Staining Patterns of Patients with NFPA

\begin{tabular}{lcc}
\hline $\begin{array}{l}\text { Positive } \\
\text { staining }\end{array}$ & $\begin{array}{c}\text { Subtype of } \\
\text { NFPA }\end{array}$ & $\begin{array}{c}\text { Number of } \\
\text { patients (\%) }\end{array}$ \\
\hline None & null-cell & $36(35.0 \%)$ \\
\hline $\mathrm{LH}$ & gonadotroph & $25(24.3 \%)$ \\
\hline $\mathrm{FSH}+\mathrm{LH}$ & gonadotroph & $18(17.5 \%)$ \\
\hline $\mathrm{FSH}$ & gonadotroph & $11(10.7 \%)$ \\
\hline $\mathrm{ACTH}$ & silent corticotroph & $3(2.9 \%)$ \\
\hline $\mathrm{GH}$ & silent somatotroph & $2(1.9 \%)$ \\
\hline $\mathrm{PRL}$ & silent lactotroph & $2(1.9 \%)$ \\
\hline $\mathrm{TSH}$ & silent thyrotroph & $1(1 \%)$ \\
\hline $\mathrm{GH}+\mathrm{PRL}$ & silent plurihormonal & $1(1 \%)$ \\
\hline $\mathrm{GH}+\mathrm{LH}$ & silent plurihormonal & $1(1 \%)$ \\
\hline $\mathrm{GH}+\mathrm{ACTH}$ & silent plurihormonal & $1(1 \%)$ \\
\hline $\mathrm{GH}+\mathrm{PRL}+\mathrm{ACTH}$ & silent plurihormonal & $1(1 \%)$ \\
\hline $\mathrm{GH}+\mathrm{PRL}+\mathrm{LH}$ & silent plurihormonal & $1(1 \%)$ \\
\hline & &
\end{tabular}


Table II: Relationships among Immunohistochemical Staining Features and Prognostic Factors in Patients with NFPAs.

\begin{tabular}{|c|c|c|c|c|c|c|}
\hline & Only FSH & All FSHs & Only LH & All LHs & FSH\&LH & $\begin{array}{c}\text { Null-cell } \\
\text { adenomas }\end{array}$ \\
\hline Number of patients & 11 & 29 & 25 & 45 & 18 & 36 \\
\hline Recurrence & $\begin{array}{c}2 \\
(18.2 \%)\end{array}$ & $\begin{array}{c}11 \\
(37.9 \%)\end{array}$ & $\begin{array}{c}15 \\
(60 \%)^{*}\end{array}$ & $\begin{array}{c}25 \\
(55.6 \%)^{\star}\end{array}$ & $\begin{array}{c}9 \\
(50 \%)^{*}\end{array}$ & $\begin{array}{c}3 \\
(8.3 \%)^{*}\end{array}$ \\
\hline Residual tumor & $10(90.9 \%)$ & $\begin{array}{c}26 \\
(89.7 \%)\end{array}$ & $\begin{array}{c}21 \\
(84 \%)\end{array}$ & $\begin{array}{c}38 \\
(84.4 \%)\end{array}$ & $16(88.9 \%)$ & $\begin{array}{c}28 \\
(77.8 \%)\end{array}$ \\
\hline Re-operation & $\begin{array}{c}5 \\
(45.5 \%)\end{array}$ & $14(43.8 \%)^{\star}$ & $\begin{array}{c}10 \\
(40 \%)\end{array}$ & $\begin{array}{c}20 \\
(44.4 \%)^{*}\end{array}$ & $\begin{array}{c}9 \\
(50 \%)^{*}\end{array}$ & $\begin{array}{c}5 \\
(13.9 \%)^{*}\end{array}$ \\
\hline Partial pituitary deficiency & $\begin{array}{c}5 \\
(45.5 \%) \\
\end{array}$ & $\begin{array}{c}12 \\
(41.4 \%) \\
\end{array}$ & $\begin{array}{c}10 \\
(40 \%)\end{array}$ & $\begin{array}{c}18 \\
(40 \%) \\
\end{array}$ & $\begin{array}{c}7 \\
(38.9 \%)\end{array}$ & $\begin{array}{c}18 \\
(50 \%) \\
\end{array}$ \\
\hline $\begin{array}{l}\text { Postoperative cavernous sinus } \\
\text { invasion }\end{array}$ & $\begin{array}{c}7 \\
(63.6 \%) \\
\end{array}$ & $\begin{array}{c}17 \\
(58.6 \%)\end{array}$ & $\begin{array}{c}13 \\
(52 \%)\end{array}$ & $\begin{array}{c}24 \\
(53.3 \%)\end{array}$ & $10(55.6 \%)$ & $\begin{array}{c}15 \\
(41.7 \%)\end{array}$ \\
\hline $\begin{array}{l}\text { Preoperative compression of } \\
\text { optic chiasm }\end{array}$ & $10(90.9 \%)$ & $\begin{array}{c}27 \\
(93.1 \%) \\
\end{array}$ & $\begin{array}{c}23 \\
(92 \%) \\
\end{array}$ & $\begin{array}{c}42 \\
(93.3 \%)\end{array}$ & $17(94.4 \%)$ & $\begin{array}{c}30 \\
(83.3 \%) \\
\end{array}$ \\
\hline $\begin{array}{l}\text { Postoperative compression of } \\
\text { optic chiasm }\end{array}$ & $\begin{array}{c}4 \\
(36.4 \%)\end{array}$ & $10(34.5 \%)^{\star}$ & $\begin{array}{c}6 \\
(24 \%)\end{array}$ & $\begin{array}{c}12 \\
(26.7 \%)\end{array}$ & $\begin{array}{c}6 \\
(33.3 \%)\end{array}$ & $\begin{array}{c}1 \\
(2.8 \%)^{\star}\end{array}$ \\
\hline
\end{tabular}

*: $p<0.05$.

some other factors have also been proposed to predict the prognosis of patients with NFPAs. A retrospective analysis of 142 patients who underwent surgery due to a NFPA showed that cavernous sinus invasion, lack of radiotherapy immediately after initial pituitary surgery, and positive immunostaining for hormones other than gonadotropins were risk factors for tumor recurrence (4). Moreover, postoperative recurrence rates were found to be significantly lower in patients who were asymptomatic than symptomatic at diagnosis of an incidentally detected NFPA (13). Furthermore, the risk of tumor recurrence was higher in patients with residual tumor and in those who did not receive radiotherapy $(13,14)$. A meta-analysis also showed that lack of radiotherapy after initial pituitary surgery was associated with an increased risk of tumor recurrence surgery (18). In addition, high Ki-67 and TUNEL labeling indices, as well as the expression of phosphoAkt, phospho-p44/42 MAPK, and PTTG1, were associated with NFPA recurrence, although that study assessed those cell proliferation markers in only 35 patients with NFPA (20).

Although NFPAs generally do not secrete any clinically significant hormones, many of these adenomas are immunohistochemically positive for FSH and/or LH $(1,7,12)$. A study involving 164 patients with NFPAs found that $69 \%$ of the adenomas were positive for FSH and/or LH (17). Brochier et al. categorized NFPAs into four groups according to their immunohistochemical features: gonadotrophic, null-cell, plurihormonal and silent adenomas; the highest recurrence rates were found in plurihormonal and silent adenomas (4). However, another study found no difference in prognosis between null-cell and gonadotroph adenomas (27). Yamada et al. reported that the rate of cavernous invasion was lower in patients with gonadotroph adenomas than other NFPAs (25). Another study carried out by Nishioka et al. showed that NFPA subtypes other than null-cell and gonadotroph adenomas were associated with a poor prognosis (19). In the present study, 54 (52.4\%) patients with NFPAs were positive for FSH and/or $\mathrm{LH}$, whereas $36(35 \%)$ patients had null-cell adenomas. Poorer clinical outcomes were more frequent in gonadotroph, particularly $\mathrm{LH}$ positive, adenomas, while optimal outcomes were more frequent in null-cell adenomas.

Silent corticotroph adenomas are NFPAs with positive staining for ACTH, but they do not cause hypercortisolemia. A study from the Mayo Clinic reported that the postoperative recurrence rate was higher among the 23 patients with $A C T H$ positive NFPA (22). A comparison of 33 NFPA patients positive for ACTH and 126 negative for ACTH found that cavernous sinus invasion and residual tumor were more common in the patients positive for ACTH (11). Cooper et al. also reported that silent corticotroph adenomas had a poorer prognosis (6). In contrast, a study involving 28 patients with ACTH positive and 60 with ACTH negative NFPAs found no significant difference in the recurrence rate (3). In the present study, only 5 of 103 NFPAs were positive for ACTH, with 3 positive only for $\mathrm{ACTH}$, and there were no significant relationships among 
ACTH staining patterns and prognostic factors. The lack of higher recurrence rates in NFPAs positive for ACTH may be due to the small numbers of these adenomas in our study.

In contrast to other studies, we found that the recurrence rate was higher for LH-positive than LH-negative adenomas. Furthermore, reoperation and postoperative optic chiasm compression rates were higher in patients with FSH-positive than FSH-negative adenomas. However, null cell adenomas showed the lowest rates of recurrence, re-operation and postoperative optic chiasm compression. To our knowledge, no previous study had shown that patients with LH positive NFPAs have a poorer prognosis than patients with $\mathrm{LH}$ negative tumors.

The large mean tumor volume $(31.2 \mathrm{~mm})$ and the associated high rates of preoperative optic chiasm compression (86.4\%), cavernous sinus invasion (78.6\%), pituitary deficiency (68.9\%), remnant tumor (81.6\%), and reoperation $31(30.1 \%)$ in the present study can be explained by the delayed diagnosis of NFPAs due to their non-functioning and silent behavior $(6,9)$. Generally, NFPAs are not associated with specific signs or symptoms, such as acromegalic phenotype, cushingoid phenotype, galactorrhea or hypogonadism, which may help in earlier diagnosis. Therefore, the most common complaints at diagnosis include the signs and symptoms arising from the mass effect, such as visual disorders, headache, and/or hypopituitarism $(4,8,10,27)$.

The main limitation of the present study was the small number of patients with NFPAs. Since only 5 patients were positive for ACTH, our finding that this group did not have a poorer prognosis was not reliable. Another important limitation was a lack of sufficient data for some patients, who did not regularly attend follow-up visits. Therefore, although none of the patients was known to have died, time-dependent survival analyses could not be performed. Furthermore, patients who received radiotherapy or medical therapies were not enrolled, because these therapies may have affected patient prognosis.

\section{- CONCLUSION}

Patients with NFPAs which have larger initial tumor volume and preoperative cavernous sinus invasion have a relatively poorer prognosis. LH positivity, either alone or in combination with other hormonal markers, was also associated with poorer prognosis. Our findings suggest the need for a comprehensive analysis of the relationship between LH positivity and poor patient prognosis, with studies including larger numbers of patients. Recognition of poor prognostic features in patients with pituitary tumors will help in their management and treatment.

\section{- REFERENCES}

1. Asa SL, Ezzat S: The cytogenesis and pathogenesis of pituitary adenomas. Endocr Rev 19(6):798-827, 1998

2. Asa SL, Kovacs K: Clinically non-functioning human pituitary adenomas. Can J Neurol Sci 19(2):228-235, 1992
3. Bradley KJ, Wass JA, Turner HE: Non-functioning pituitary adenomas with positive immunoreactivity for ACTH behave more aggressively than $\mathrm{ACTH}$ immunonegative tumours but do not recur more frequently. Clin Endocrinol (Oxf) 58(1):5964, 2003

4. Brochier S, Galland F, Kujas M, Parker F, Gaillard S, Raftopoulos C, Young J, Alexopoulou O, Maiter D, Chanson $\mathrm{P}$ : Factors predicting relapse of nonfunctioning pituitary macroadenomas after neurosurgery: A study of 142 patients. Eur J Endocrinol 163(2):193-200, 2010

5. Colao A, Grasso LF, Pivonello R, Lombardi G: Therapy of aggressive pituitary tumors. Expert Opin Pharmacother 12(10):1561-1570, 2011

6. Cooper O, Ben-Shlomo A, Bonert V, Bannykh S, Mirocha J, Melmed S: Silent corticogonadotroph adenomas: Clinical and cellular characteristics and long-term outcomes. Horm Cancer 1(2):80-92, 2010

7. Cooper O, Melmed S: Subclinical hyperfunctioning pituitary adenomas: The silent tumors. Best Pract Res Clin Endocrinol Metab 26(4):447-460, 2012

8. Ferrante $E$, Ferraroni M, Castrignano T, Menicatti L, Anagni M, Reimondo G, Del Monte P, Bernasconi D, Loli P, FaustiniFustini M, Borretta G, Terzolo M, Losa M, Morabito A, Spada A, Beck-Peccoz P, Lania AG: Non-functioning pituitary adenoma database: $A$ useful resource to improve the clinical management of pituitary tumors. Eur J Endocrinol 155(6):823829, 2006

9. Greenman Y, Ouaknine G, Veshchev I, Reider-Groswasser II, Segev Y, Stern N: Postoperative surveillance of clinically nonfunctioning pituitary macroadenomas: Markers of tumour quiescence and regrowth. Clin Endocrinol (Oxf) 58(6):763769, 2003

10. Greenman Y, Stern N: Non-functioning pituitary adenomas. Best Pract Res Clin Endocrinol Metab 23(5):625-638, 2009

11. loachimescu AG, Eiland L, Chhabra VS, Mastrogianakis GM, Schniederjan MJ, Brat D, Pileggi AV, Oyesiku NM: Silent corticotroph adenomas: Emory University cohort and comparison with ACTH-negative nonfunctioning pituitary adenomas. Neurosurgery 71(2):296-304, 2012

12. Klibanski A: Nonsecreting pituitary tumors. Endocrinol Metab Clin North Am 16(3):793-804, 1987

13. Losa M, Donofrio CA, Barzaghi R, Mortini P: Presentation and surgical results of incidentally discovered nonfunctioning pituitary adenomas: Evidence for a better outcome independently of other patients' characteristics. Eur J Endocrinol 169(6):735742, 2013

14. Losa M, Mortini P, Barzaghi R, Ribotto P, Terreni MR, Marzoli SB, Pieralli S, Giovanelli M: Early results of surgery in patients with nonfunctioning pituitary adenoma and analysis of the risk of tumor recurrence. J Neurosurg 108(3):525-532, 2008

15. McCormack Al, Wass JA, Grossman AB: Aggressive pituitary tumours: The role of temozolomide and the assessment of MGMT status. Eur J Clin Invest 41(10):1133-1148, 2011

16. Meij BP, Lopes MB, Ellegala DB, Alden TD, Laws ER Jr: The long-term significance of microscopic dural invasion in 354 patients with pituitary adenomas treated with transsphenoidal surgery. J Neurosurg 96(2):195-208, 2002 
17. Messerer M, De Battista JC, Raverot G, Kassis S, Dubourg J, Lapras V, Trouillas J, Perrin G, Jouanneau E: Evidence of improved surgical outcome following endoscopy for nonfunctioning pituitary adenoma removal. Neurosurg Focus 30(4): E11, 2011

18. Murad MH, Fernandez-Balsells MM, Barwise A, GallegosOrozco JF, Paul A, Lane MA, Lampropulos JF, Natividad I, Perestelo-Perez L, Ponce de Leon-Lovaton PG, Albuquerque FN, Carey J, Erwin PJ, Montori VM: Outcomes of surgical treatment for nonfunctioning pituitary adenomas: A systematic review and meta-analysis. Clin Endocrinol (Oxf) 73(6):777791,2010

19. Nishioka H, Inoshita N, Sano T, Fukuhara N, Yamada S: Correlation between histological subtypes and MRI findings in clinically nonfunctioning pituitary adenomas. Endocr Pathol 23(3):151-156, 2012

20. Noh TW, Jeong HJ, Lee MK, Kim TS, Kim SH, Lee EJ: Predicting recurrence of nonfunctioning pituitary adenomas. J Clin Endocrinol Metab 94(11):4406-4413, 2009

21. Roelfsema F, Biermasz NR, Pereira AM: Clinical factors involved in the recurrence of pituitary adenomas after surgical remission: A structured review and meta-analysis. Pituitary 15(1):71-83, 2012

22. Scheithauer BW, Jaap AJ, Horvath E, Kovacs K, Lloyd RV, Meyer FB, Laws ER Jr, Young WF Jr: Clinically silent corticotroph tumors of the pituitary gland. Neurosurgery 47(3):723-730, 2000
23. Trouillas J, Roy P, Sturm N, Dantony E, Cortet-Rudelli C, Viennet G, Bonneville JF, Assaker R, Auger C, Brue T, Cornelius A, Dufour H, Jouanneau E, Francois P, Galland F, Mougel F, Chapuis F, Villeneuve L, Maurage CA, Figarella-Branger D, Raverot G, Barlier A, Bernier M, Bonnet F, Borson-Chazot F, Brassier G, Caulet-Maugendre S, Chabre O, Chanson P, Cottier JF, Delemer B, Delgrange E, Di Tommaso L, Eimer S, Gaillard S, Jan M, Girard JJ, Lapras V, Loiseau H, Passagia JG, Patey M, Penfornis A, Poirier JY, Perrin G, Tabarin A: A new prognostic clinicopathological classification of pituitary adenomas: A multicentric case-control study of 410 patients with 8 years post-operative follow-up. Acta Neuropathol 126(1):123-135, 2013

24. Yamada S, Kovacs K, Horvath E, Aiba T: Morphological study of clinically nonsecreting pituitary adenomas in patients under 40 years of age. J Neurosurg 75(6):902-905, 1991

25. Yamada S, Ohyama K, Taguchi M, Takeshita A, Morita K, Takano K, Sano T: A study of the correlation between morphological findings and biological activities in clinically nonfunctioning pituitary adenomas. Neurosurgery 61(3):580-585, 2007

26. Yamaguchi-Okada M, Inoshita N, Nishioka H, Fukuhara N, Yamada S: Clinicopathological analysis of nonfunctioning pituitary adenomas in patients younger than 25 years of age. J Neurosurg Pediatr 9(5):511-516, 2012

27. Young WF Jr, Scheithauer BW, Kovacs KT, Horvath E, Davis $\mathrm{DH}$, Randall RV: Gonadotroph adenoma of the pituitary gland: A clinicopathologic analysis of 100 cases. Mayo Clin Proc 71(7):649-656, 1996

28. Zada G, Woodmansee WW, Ramkissoon S, Amadio J, Nose V, Laws ER Jr: Atypical pituitary adenomas: Incidence, clinical characteristics, and implications. J Neurosurg 114(2):336344, 2011 